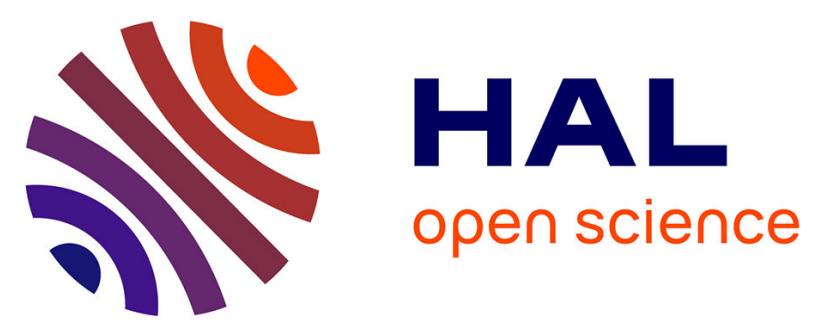

\title{
Targeting of immunosuppressive myeloid cells from glioblastoma patients by modulation of size and surface charge of lipid nanocapsules
}

Laura Pinton, Sara Magri, Elena Masetto, Marina Vettore, Ilaria Schibuola, Vincenzo Ingangi, Ilaria Marigo, Kevin Matha, Jean-Pierre Benoit, Alessandro Della Puppa, et al.

\section{To cite this version:}

Laura Pinton, Sara Magri, Elena Masetto, Marina Vettore, Ilaria Schibuola, et al.. Targeting of immunosuppressive myeloid cells from glioblastoma patients by modulation of size and surface charge of lipid nanocapsules. Journal of Nanobiotechnology, 2020, 18 (31), pp.1-12. 10.1186/s12951-02000589-3 . hal-02482506

\section{HAL Id: hal-02482506 \\ https://univ-angers.hal.science/hal-02482506}

Submitted on 18 Feb 2020

HAL is a multi-disciplinary open access archive for the deposit and dissemination of scientific research documents, whether they are published or not. The documents may come from teaching and research institutions in France or abroad, or from public or private research centers.
L'archive ouverte pluridisciplinaire HAL, est destinée au dépôt et à la diffusion de documents scientifiques de niveau recherche, publiés ou non, émanant des établissements d'enseignement et de recherche français ou étrangers, des laboratoires publics ou privés. 


\title{
Targeting of immunosuppressive myeloid cells from glioblastoma patients by modulation of size and surface charge of lipid nanocapsules
}

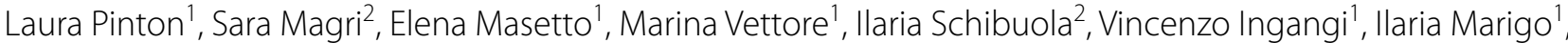 \\ Kevin Matha ${ }^{3,4}$, Jean-Pierre Benoit ${ }^{3,4}$, Alessandro Della Puppa ${ }^{5,8}$, Vincenzo Bronte ${ }^{6}$, Giovanna Lollo ${ }^{7}$ \\ and Susanna Mandruzzato ${ }^{1,2^{*}}$
}

\begin{abstract}
Background: Myeloid derived suppressor cells (MDSCS) and tumor-associated macrophages (TAMs) are two of the major players involved in the inhibition of anti-tumor immune response in cancer patients, leading to poor prognosis. Selective targeting of myeloid cells has therefore become an attractive therapeutic strategy to relieve immunosuppression and, in this frame, we previously demonstrated that lipid nanocapsules (LNCs) loaded with lauroyl-modified gemcitabine efficiently target monocytic MDSCs in melanoma patients. In this study, we investigated the impact of the physico-chemical characteristics of LNCs, namely size and surface potential, towards immunosuppressive cell targeting. We exploited myeloid cells isolated from glioblastoma patients, which play a relevant role in the immunosuppression, to demonstrate that tailored nanosystems can target not only tumor cells but also tumor-promoting cells, thus constituting an efficient system that could be used to inhibit their function.
\end{abstract}

Results: The incorporation of different LNC formulations with a size of $100 \mathrm{~nm}$, carrying overall positive, neutral or negative charge, was evaluated on leukocytes and tumor-infiltrating cells freshly isolated from glioblastoma patients. We observed that the maximum LNC uptake was obtained in monocytes with neutral $100 \mathrm{~nm}$ LNCs, while positively charged $100 \mathrm{~nm}$ LNCs were more effective on macrophages and tumor cells, maintaining at low level the incorporation by T cells. The mechanism of uptake was elucidated, demonstrating that LNCs are incorporated mainly by caveolae-mediated endocytosis.

Conclusions: We demonstrated that LNCs can be directed towards immunosuppressive cells by simply modulating their size and charge thus providing a novel approach to exploit nanosystems for anticancer treatment in the frame of immunotherapy.

Keywords: Myeloid cells, Lipid nanocapsules, Glioma, Myeloid derived suppressor cells, Immunosuppression

\section{Background}

The recent implementation of nanosystems with different chemical and physical features and loaded with a variety of compounds offers promising opportunities

\footnotetext{
*Correspondence: susanna.mandruzzato@unipd.it

2 Department of Surgery, Oncology and Gastroenterology, University of Padova, Via Gattamelata 64, 35128 Padua, Italy
}

Full list of author information is available at the end of the article to target selected cell populations in cancer [1]. The improved anti-tumor effects of nanomedicine has been widely ascribed to the direct cytotoxicity of chemotherapeutics on cancer cells, due to elevated drug concentrations in tumor tissue via passive- and/ or tumor-targeting and favorable pharmacokinetics. In addition, the manipulation of the immune system significantly affects the efficacy of cancer therapies. The contribution of nanomedicine to either direct 
stimulation of the immune system by immunogenic cell death or reduction in immunosuppressive populations has the potential to increase antitumor immune response by regulating specific pathways within immune cell populations acting on their composition, geometry, or surface properties [2-4].

So far, the effect of size and surface charge has been explored for nanostructures targeting tumoral tissues and tumor microenvironment [5]. In regard to the impact of particle size on solid tumors, only nanoparticles smaller than $100 \mathrm{~nm}$ accumulated efficiently in poorly permeable tumors [6], while surface potential influences nanoparticle recognition by blood circulating and tissue phagocytes [7]. However, only few studies have explored the effect of these parameters on immunosuppressive myeloid cells.

Myeloid-derived suppressor cells (MDSCs) and tumorassociated macrophages (TAMs) constitute two of the main players involved in the induction of immune tolerance in cancer patients. MDSCs are a heterogeneous population of myeloid cells able to inhibit innate and adaptive immunity in cancer patients and mouse models [8]. Several populations of human MDSCs have been described, which, based on their phenotypic and morphological features, can be divided into three main subsets: monocytic MDSCs (M-MDSCs), polymorphonuclear MDSCs (PMN-MDSCs) and early-stage MDSCs (eMDSCs) [8]. TAMs are particularly abundant in the tumor mass of different tumors and can rapidly change their phenotype and function in response to local environmental stimuli, acquiring immunosuppressive and pro-tumoral properties [9] and hence they have been associated to poor clinical outcome [10]. Selective targeting of myeloid cells has been advanced as therapeutic strategy to relieve immunosuppression in patients and increase the response to conventional and immunotherapy treatments [11]. In this context, identification of a nanosystem selectively targeting tumor-promoting myeloid cells could represent a new tool to block their activity with the potential to be used in combination therapy with immune stimulating agents.

We previously demonstrated in a glioma rat model that lipid nanocapsules (LNCs) loaded with paclitaxel were able to inhibit multidrug resistance in glioma cells and to reduce tumor progression [12, 13]. Moreover, we also showed that an LNC formulation is endowed with a preferential targeting of myeloid cells. We found that LNCs loaded with a lauroyl-modified form of gemcitabine (GemC12) were able to target M-MDSCs, attenuate tumor-associated immunosuppression, and increase the efficacy of adoptive $\mathrm{T}$ cell therapy in lymphoma and melanoma-bearing mice. Moreover, the treatment of monocytes from melanoma patients with GemC12loaded LNCs reduced their immunosuppressive properties in vitro [14].
Starting from these results, in this work we studied the impact of the physico-chemical properties, namely size and surface potential, of LNC formulations, already tested in mouse models [13-15], to increase their targeting abilities towards MDSCs and TAMs freshly isolated from glioblastoma (grade IV glioma, GBM) patients in which several immunosuppressive mechanisms have been documented. For example, the expansion of MDSC subsets has been reported in the peripheral blood of these patients as compared to healthy donors (HDs) [16], while at the tumor site, an abundant infiltrate of myeloid origin has been observed, mainly characterized by macrophages $[17,18]$, which were shown to possess immunosuppressive activity toward T cells [18-21]. TAMs comprise both resident microglia (MG) and macrophages of blood origin (bone marrow-derived macrophages-BMDM), and we recently demonstrated that in the center of GBM tumor mass BMDMs are abundant and endowed with a strong immune suppressive activity [18]. We therefore selected GBM as a model to test the targeting of optimized nanosystems towards immunosuppressive cells, with the future goal of loading these nanoparticles with selected drugs able to deplete or inhibit the activity of MDSCs and TAMs.

\section{Results}

\section{The LNC internalization by blood leukocyte subsets} depends on particle size

Given the importance of $\mathrm{T}$ cell activation and the negative role of myeloid cells in anti-tumor immune response, we rationally modified LNC formulations to target myeloid cells, while reducing the uptake by T cells. LNCs, prepared as previously described, were composed of FDA-approved excipients showing a good safety record and a tunable size (between 20 and $100 \mathrm{~nm}$ ) [22, 23]. In this study, we tested LNCs with different physico-chemical properties, i.e. variable size and surface charge, to modulate cell uptake $[4,24,25]$.

First, we tested the uptake of LNCs with $25 \mathrm{~nm}$, $50 \mathrm{~nm}$, and $100 \mathrm{~nm}$ size, neutrally charged (Table 1),

\begin{tabular}{|c|c|c|c|}
\hline Formulation & Size $(\mathrm{nm})$ & PI & Zeta Potential $(\mathrm{mV})$ \\
\hline $25 \mathrm{~nm}$ LNCs neutral & $25 \pm 1$ & $<0.1$ & $0 \pm 1$ \\
\hline 50 nm LNCs neutral & $53 \pm 4$ & $<0.1$ & $-4 \pm 1$ \\
\hline 100 nm LNCs neutral & $101 \pm 3$ & $<0.1$ & $-3 \pm 0.5$ \\
\hline \multirow[t]{3}{*}{100 nm LNCs negative } & $102 \pm 3$ & $<0.1$ & $-20 \pm 3$ \\
\hline & $99 \pm 3$ & $<0.1$ & $+6 \pm 2$ \\
\hline & $102 \pm 1$ & $<0.1$ & $+16 \pm 3$ \\
\hline \multirow[t]{2}{*}{100 nm LNCs positive } & $92 \pm 7$ & $<0.1$ & $+25 \pm 2$ \\
\hline & $95 \pm 8$ & $<0.1$ & $+31 \pm 3$ \\
\hline
\end{tabular}



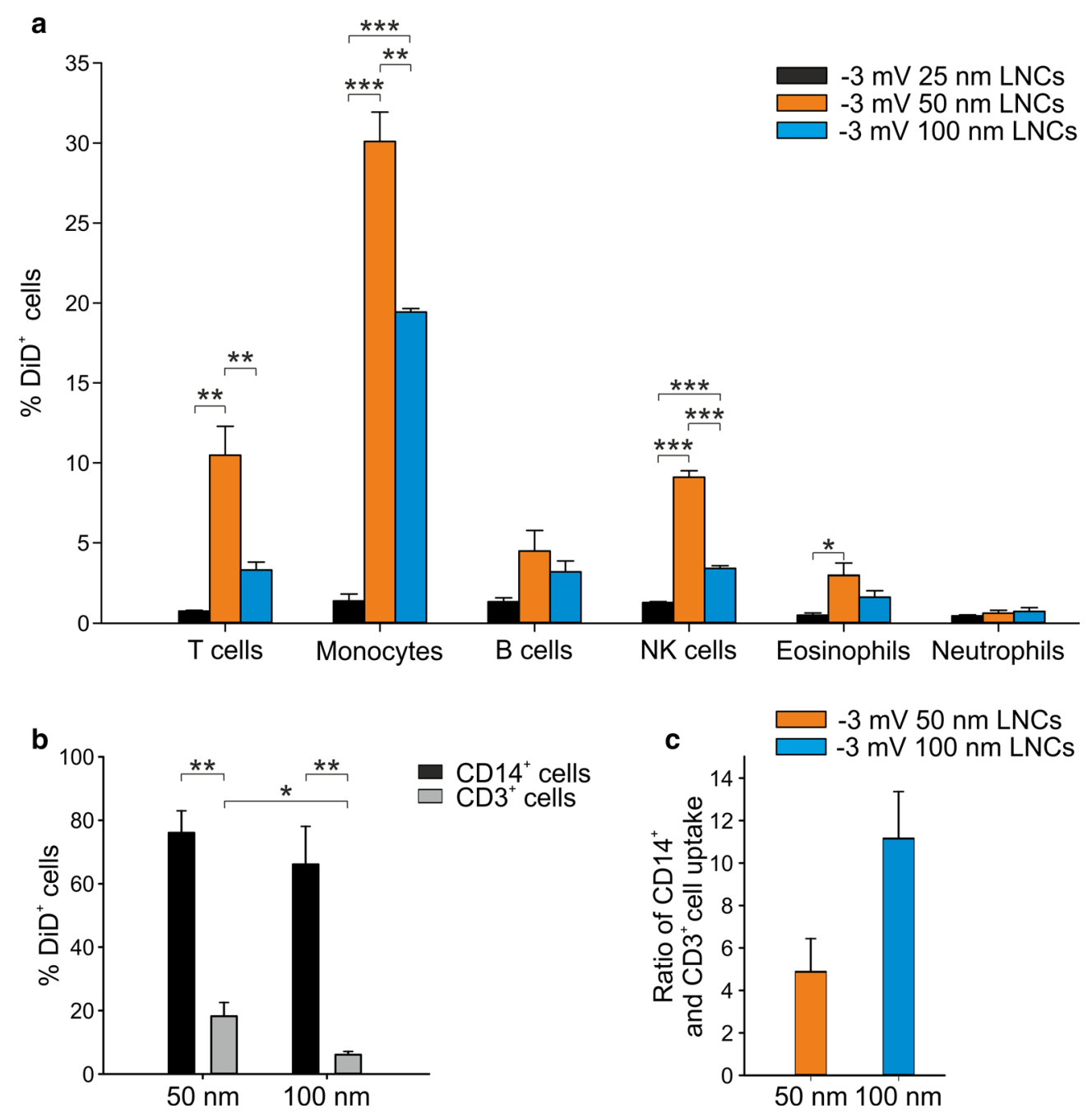

Fig. 1 Incorporation of LNCs of different size by peripheral blood leukocytes (PBLs). a PBLs from 3 HDs were treated for 90' with neutral DiD-LNCs of different size ( $25 \mathrm{~nm}$ in black, $50 \mathrm{~nm}$ in orange and $100 \mathrm{~nm}$ in blue), with DiD at $50 \mathrm{ng} / \mathrm{ml}$ and then stained with mAbs (anti-CD3, anti-CD14, anti-CD19, anti-CD56, anti-CD11b, anti-CD16) for flow cytometry analysis. Blank-LNCs were used as negative control. b PBLs from 3 HDs were treated for $3 \mathrm{~h}$ with $50 \mathrm{~nm}$ and $100 \mathrm{~nm}$ DiD-LNCs at a DiD concentration of $50 \mathrm{ng} / \mathrm{ml}$ and stained with anti-CD14 and anti-CD3 mAbs to identify monocyte (black) and T lymphocyte (grey) uptake. c The histogram in panel B shows the ratio between the percentage of DiD ${ }^{+}$cells among $\mathrm{CD}_{14}{ }^{+}$and $\mathrm{CD}^{+}{ }^{+}$populations. Mean and standard error (SE) of 3 independent experiments are reported. Student t-test was performed, ${ }^{*} \mathrm{P} \leq 0.05$; ${ }^{* * P} \leq 0.01 ;{ }^{* *} \mathrm{P} \leq 0.001$

and loaded with the fluorescent dye DiD (DiD-LNC). Incorporation by leukocyte subsets present in the peripheral blood of HDs was evaluated by multicolor flow cytometry, with mAbs directed against markers present on the cell surface of different leukocyte cell subsets and by assessing the signal emitted by $\mathrm{DiD}$ in $\mathrm{T}$ cells $\left(\mathrm{CD}^{+}\right)$, monocytes $\left(\mathrm{CD} 14^{+}\right)$, B cells $\left(\mathrm{CD} 19^{+}\right)$, NK cells $\left(\mathrm{CD} 56^{+}\right)$, eosinophils $\left(\mathrm{CD} 11 \mathrm{~b}^{+} \mathrm{CD} 16^{-}\right)$, and polymorphonuclear cells $\left(\mathrm{PMN}, \mathrm{CD} 11 \mathrm{~b}^{+} \mathrm{CD} 16^{+}\right)$. BlankLNCs were used as control. As shown in Fig. 1a, the incorporation of $25 \mathrm{~nm}$ LNCs was very low in all the considered leukocyte populations, while $50 \mathrm{~nm}$ LNCs showed the highest uptake in the analyzed subsets and in particular in monocytes $(30.1 \pm 3.2 \%)$. The $100 \mathrm{~nm}$ LNCs did not reach the same uptake of $50 \mathrm{~nm}$ LNCs on monocytes $(19.4 \pm 0.4 \%)$ but allowed the reduction in internalization by $\mathrm{T}$ lymphocytes $(10.5 \pm 3.1 \%$ with $50 \mathrm{~nm}$ LNCs vs $3.3 \pm 0.9 \%$ with $100 \mathrm{~nm}$ LNCs). We excluded from the analysis the $25 \mathrm{~nm}$ LNCs and further investigated the internalization properties of neutral $50 \mathrm{~nm}$ and $100 \mathrm{~nm}$ LNCs, focusing on monocytes and $\mathrm{T}$ cells, and increasing the incubation time from $90^{\prime}$ to $3 \mathrm{~h}$ in order to reach the highest LNC internalization (Fig. 1b). Under these experimental conditions, both LNC formulations reached comparable high levels of internalization in monocytes, but the incorporation by 
Table 2 LNCs 25, 50 \& $100 \mathrm{~nm}$ formulations

\begin{tabular}{|c|c|c|c|}
\hline \multirow[t]{2}{*}{ Excipient (mg) } & \multicolumn{3}{|c|}{ LNC size $(\mathrm{nm})$} \\
\hline & 25 & 50 & 100 \\
\hline Labrafac ${ }^{\circledR}$ & 600 & 1116.8 & 1800 \\
\hline Kolliphor ${ }^{\circledR}$ HS15 & 1800 & 916.8 & 950 \\
\hline Span 80 & 300 & 450 & 300 \\
\hline MilliQ water & 1300 & 1516.8 & 950 \\
\hline $\mathrm{NaCl}$ & 54 & 54 & 54 \\
\hline Quenching water & 2000 & 2000 & 2000 \\
\hline
\end{tabular}

T cells was significantly lower when $100 \mathrm{~nm}$ LNCs were used (Fig. 1b). By calculating the ratio between the signal of DiD in monocytes and T cells, we observed that $100 \mathrm{~nm}$ LNCs allowed increasing specificity of LNC targeting towards monocytes (mean ratio of $4.9 \pm 2.7$ for $50 \mathrm{~nm}$ LNCs vs $11.2 \pm 3.8$ for $100 \mathrm{~nm}$ LNCs) (Fig. 1c). Therefore, neutral $100 \mathrm{~nm}$ LNC formulation was chosen for further experiments.

\section{Effect of $100 \mathrm{~nm}$ LNC surface charge on the internalization} ability of peripheral blood leukocytes (PBLs)

We next set out to assess the surface charge of $100 \mathrm{~nm}$ LNCs to increase the specific uptake by monocytes compared to all the other main leukocyte populations. To this aim, we compared $100 \mathrm{~nm}$ neutral LNCs $(-3 \mathrm{mV})$ to LNCs with a slightly positive surface charge. The loading of cationic surfactant DDAB in nanosystems did not alter the size of the systems, while it affected the surface properties of the LNCs. The physico-chemical characteristics are summarized in Table 2.

After $3 \mathrm{~h}$ of incubation of PBLs with DiD-loaded LNCs (Fig. 2a), the internalization by $\mathrm{T}$ cells was very low and comparable in all the tested LNC formulations, while in monocytes the incorporation was always significantly higher than that of $\mathrm{T}$ cells, and had a trend toward an increase as the positive charge augmented $\left(98.6 \pm 1.2 \%\right.$ of $\mathrm{DiD}^{+}$monocytes using $+31 \mathrm{mV}$ LNCs vs $90.7 \pm 4.7 \%$ with neutral LNCs; $82.0 \pm 16.5 \%$ with $+6 \mathrm{mV}$ LNCs; $85.1 \pm 12.9 \%$ with $+16 \mathrm{mV}$ LNCs; $95.6 \pm 4.3 \%$ with $+25 \mathrm{mV}$ LNCs).

We therefore tested the internalization of $100 \mathrm{~nm}$ positive LNCs $(+31 \mathrm{mV})$ by all leukocyte subsets present in the peripheral blood of HDs and compared the results to neutral LNC formulation (Fig. 2b). Monocytes showed the highest incorporation of positive $(+31 \mathrm{mV})$ LNCs $(92.0 \pm 1.4 \%)$, but a high uptake was also noticed for B lymphocytes $(43.7 \pm 19.2 \%)$, an effect that was not observed using neutral LNCs $(2.1 \pm 0.3 \%)$. This could lead to a deleterious consequence on the patient's immune response if LNCs loaded with a cytotoxic drug were used. We thus selected the $100 \mathrm{~nm}$ neutral surface

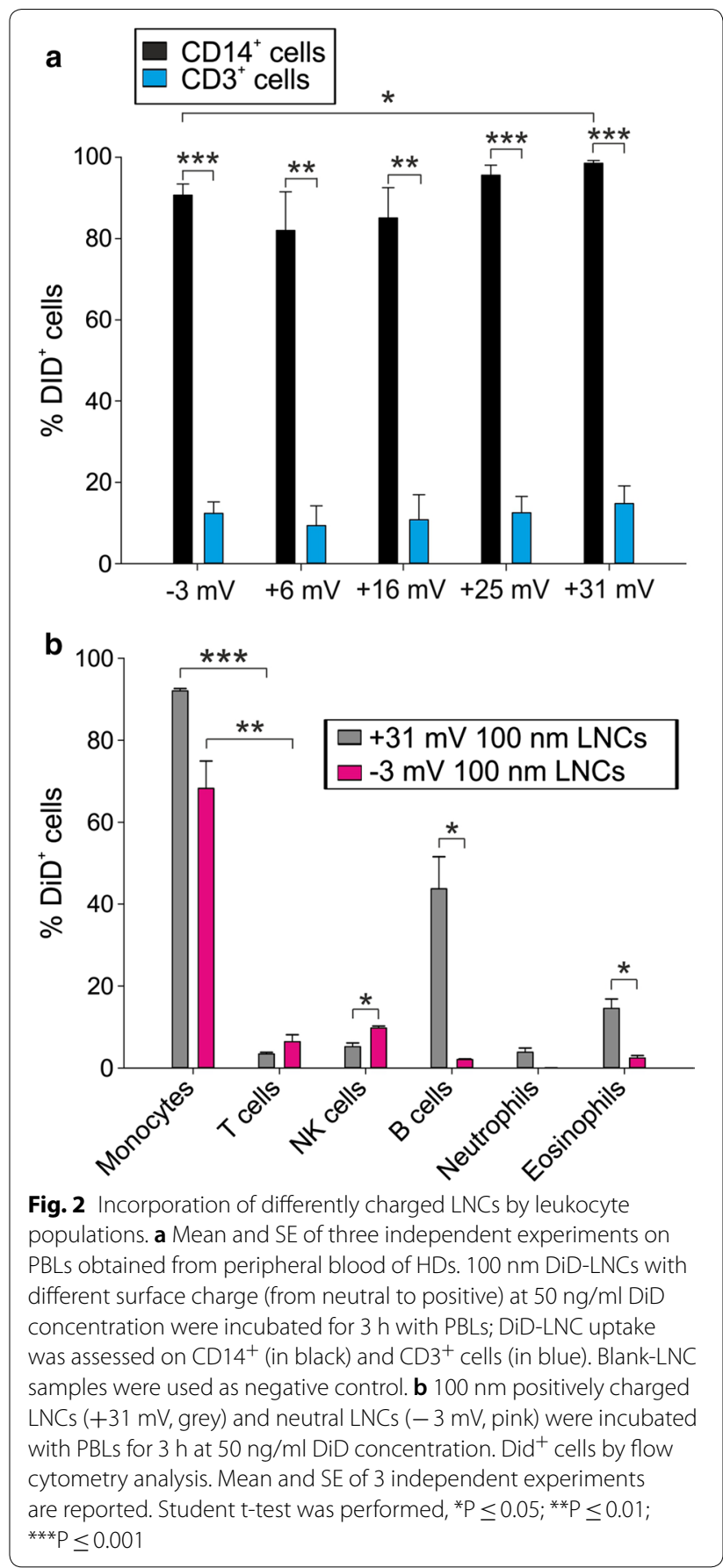

charge formulation to target monocytes in the peripheral blood and avoid incorporation by B cells.

\section{Targeting circulating immunosuppressive cells in GBM patients by $100 \mathrm{~nm}$ neutral LNCs}

Data from literature [16] and our own results (Pinton et al., unpublished) indicate that GBM patients have 


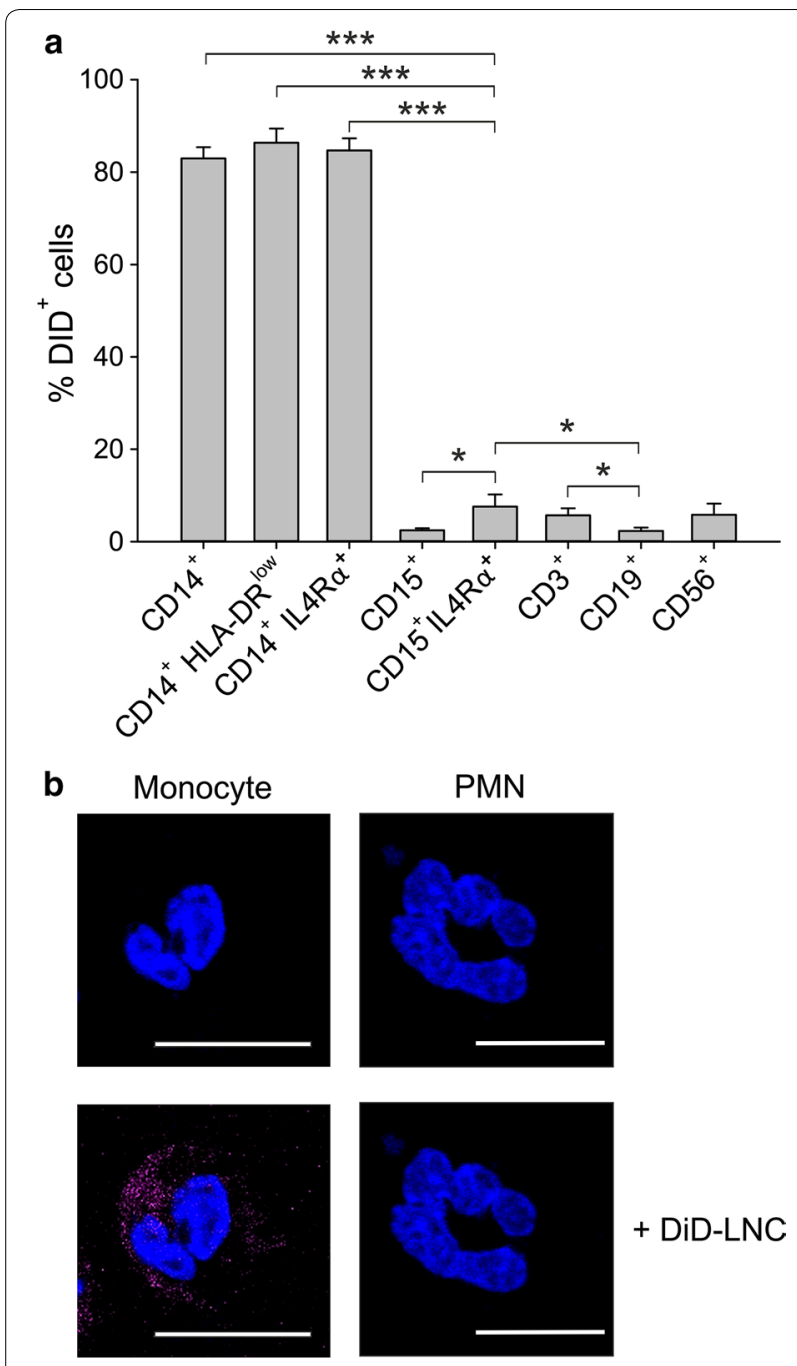

Fig. 3 Uptake of neutral LNCs by leukocyte subsets in the peripheral blood of GBM patients. a Mean and SE of PBLs from 7 GBM patients incubated with $100 \mathrm{~nm}$ neutral LNCs for $3 \mathrm{~h}$ at a DiD concentration of $50 \mathrm{ng} / \mathrm{ml}$. DiD-LNC uptake was evaluated by flow cytometry. Mann-Whitney test was performed, ${ }^{*} P \leq 0.05 ;{ }^{* * P} \leq 0.01 ;{ }^{* * *} P \leq 0.001$. b PBMCs and PMNs isolated from GBM patients were incubated with $100 \mathrm{~nm}$ neutral LNCs for $3 \mathrm{~h}$ at a DiD concentration of $50 \mathrm{ng} /$ $\mathrm{ml}$. Then cells were washed and plated, nuclei were counterstained with DAPI, and the slides were analyzed by confocal microscopy. Representative fluorescence images (monocyte and PMN) are shown at a magnification of 150X. Cell size is reported by scale bar $(10 \mu \mathrm{m})$

a significant expansion in circulating MDSC populations. We thus tested the uptake of the $100 \mathrm{~nm}$ neutral LNC formulation on leukocyte subsets present in the peripheral blood of these patients, extending the analysis to three MDSC subsets: two monocytic subsets (identified as $\mathrm{CD}_{1} 4^{+} \mathrm{IL} 4 \mathrm{R}^{+}$and $\mathrm{CD}^{+} 4^{+}$HLA-DR $^{\text {low }}$ cells) and one PMN type $\left(\mathrm{CD} 15^{+} \mathrm{IL}_{\mathrm{LR}} \alpha^{+}\right)$[8]. Following PBL incubation with DiD-loaded LNCs, maximum
LNC internalization was observed by total monocytes (CD14 ${ }^{+}$cells: $\left.83.0 \pm 6.4 \%\right)$ and by monocyte subsets $\mathrm{CD} 4^{+}$HLA-DR ${ }^{\text {low }}(86.4 \pm 8.2 \%)$ and $\mathrm{CD} 4^{+} \mathrm{IL} \mathrm{IR \alpha}^{+}$ $(84.7 \pm 6.9 \%)$ cells, corresponding to monocytic MDSCs (Fig. 3a), thus highlighting that this nanocarrier system could efficiently target immunosuppressive myeloid cells in GBM patients, while sparing lymphocyte subsets that, instead, showed very low uptake. A lower level of incorporation was observed in PMN-MDSCs, defined as $\mathrm{CD} 15^{+}$IL4R $\alpha^{+}$cells, as compared to the two monocytic subsets; it should be noted that this immunosuppressive granulocytic population shows a significantly higher LNC uptake as compared to total PMNs (defined as $\mathrm{CD} 15^{+}$cells) $\left(7.6 \pm 7 \% \mathrm{DiD}^{+}\right.$cells in $\mathrm{CD} 15^{+} \mathrm{IL}_{4 \mathrm{R} \alpha^{+}}$vs $2.4 \pm 1.2 \% \mathrm{DiD}^{+}$cells in PMNs), thus reinforcing the efficacy of LNCs in targeting immunosuppressive cells. To confirm intracellular localization of LNCs, we performed confocal analysis in isolated peripheral blood mononuclear cells (PBMCs) and PMN fractions, and observed that DiD-loaded lipid nanoparticles are internalized by monocytes showing cytoplasmic localization, while no uptake by granulocytes was observed (Fig. 3b).

\section{Mechanism of LNC internalization by circulating monocytes}

To gain evidence about the mechanisms involved in $100 \mathrm{~nm}$ neutral LNC internalization by monocytes, PBLs from GBM patients were treated with inhibitors of different uptake mechanisms and their effect was verified on particle internalization. Colchicine was used to inhibit pinocytosis [26], cytochalasin B as inhibitor of phagocytosis [26], LY294002 and Wortmannin as inhibitors of fluid phase pinocytosis and FcR-mediated phagocytosis $[27,28]$, and nystatin as inhibitor of caveolae-mediated endocytosis [29]. Results indicate that nystatin is the most effective inhibitor, causing a significant reduction in the uptake of monocytes (Fig. 4a). Another inhibitor that showed a trend toward a reduced LNC internalization by monocytes is colchicine, although its effect did not reach the same level observed with nystatin, lacking statistical significance. Altogether, these results indicate that $100 \mathrm{~nm}$ neutral LNCs are mainly internalized by monocytes from GBM patients through caveolae-mediated endocytosis. We also visualized the effect of nystatin on LNC uptake by PBMCs from three glioma patients, by means of confocal microscopy. Monocytes were enriched by adhesion onto microscope slides and further selected by nuclear morphology; following nystatin treatment, we observed a remarkable reduction in the internalization of DiD-loaded LNCs (Fig. 4b), thus confirming the results obtained by flow cytometry. 


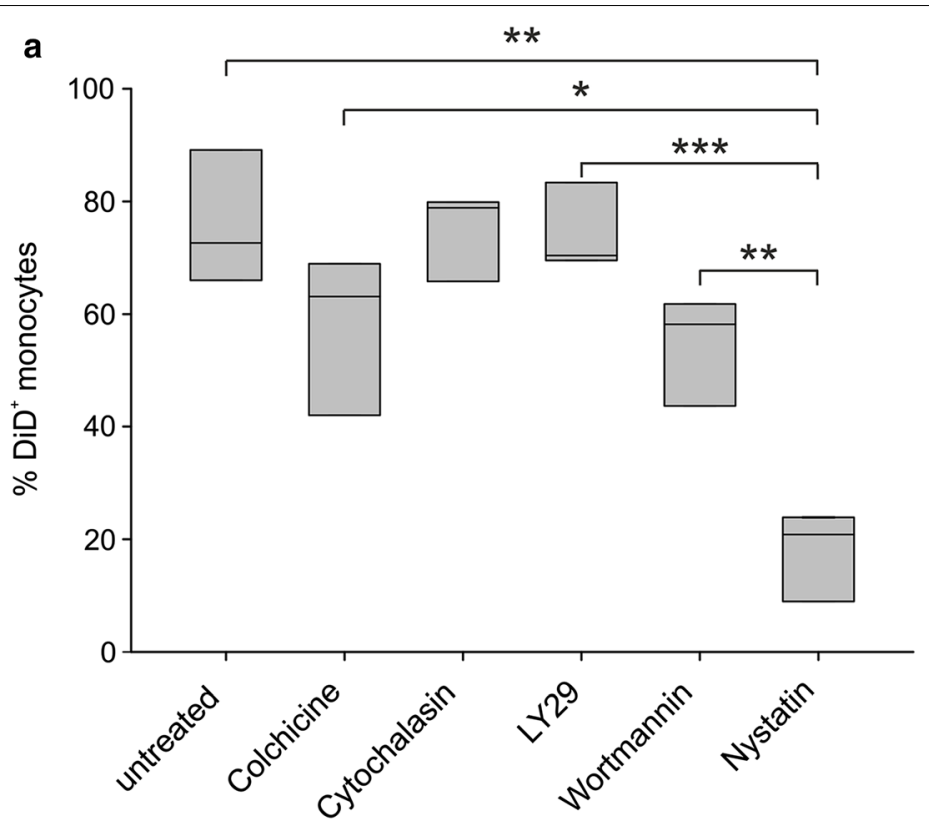

b

untreated

Nystatin
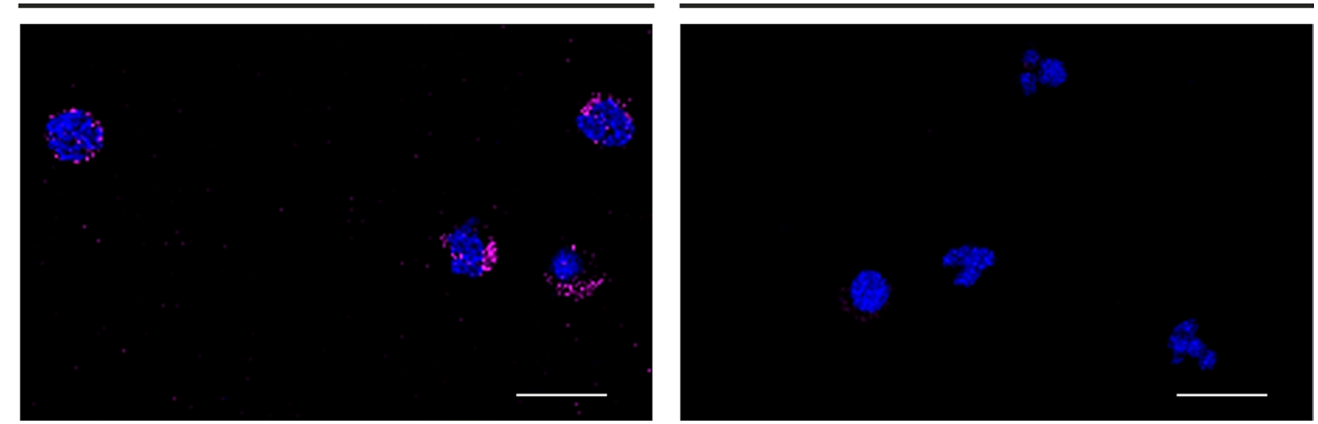

Fig. 4 Effect of different inhibitors on LNC uptake by circulating monocytes. a PBLs from 3 GBM patients were incubated for $2 \mathrm{~h}$ with $100 \mu \mathrm{g} / \mathrm{ml}$ colchicine or $10 \mu \mathrm{g} / \mathrm{ml}$ cytochalasin B, 45' with $50 \mu \mathrm{M}$ LY294002, 30' with $100 \mathrm{nM}$ Wortmannin, 15' with $100 \mathrm{U} / \mathrm{ml}$ Nystatin. DiD-loaded LNCs were added to PBLs at $50 \mathrm{ng} / \mathrm{ml}$ DiD for $3 \mathrm{~h}$ and then stained for cytometry analysis. Box plots show the range of DiD ${ }^{+}$cells in the subsets analyzed in 3 experiments. Student t-test was performed, ${ }^{*} P \leq 0.05 ;{ }^{* *} P \leq 0.01 ;{ }^{* *} \mathrm{P} \leq 0.001$. b Representative images of confocal analysis of PBMCs from $3 \mathrm{GBM}$ patients incubated with Nystatin and DiD-loaded LNCs at $50 \mathrm{ng} / \mathrm{ml}$ DiD for $3 \mathrm{~h}$. Cells were stained with DAPI, and slides were analyzed at a $63 \times$ magnification. Cell size is reported by scale bar $(10 \mu \mathrm{m})$

\section{Evaluation of LNC uptake by the cells present in GBM microenvironment}

Since $100 \mathrm{~nm}$ neutral LNCs efficiently target myeloid cells in the blood of GBM patients, we evaluated whether the same nanosystem could be incorporated by different cell subsets present in the tumor microenvironment. In fact, our recent results highlight the presence of an abundant leukocyte infiltrate of myeloid origin, mainly constituted by macrophages, as a main characteristic in GBM. We demonstrated that only macrophages of bone marrow origin, and not the resident microglial cells (MG), were endowed with a strong immunosuppressive activity [18]. In fact, during tumor growth, macrophages originating from bone-marrow (BMDM) are recruited to the tumor, and can be distinguished by tissue resident MG through a marker combination in multicolor flow cytometry (Fig. 5a upper panels) $[17,18]$. We therefore tested the incorporation of different LNC formulations with a size of $100 \mathrm{~nm}$, carrying overall positive, neutral or negative charge, in the cell suspension freshly obtained from tumor tissue and analyzed the incorporation by BMDM, MG, tumor cells (CD45- cells), PMNs, and lymphocytes. The maximum LNC uptake was obtained for macrophages (BMDM and $M G$ ) and tumor cells when positively charged LNCs were used; the low level the incorporation by $\mathrm{T}$ cells was comparable across different 


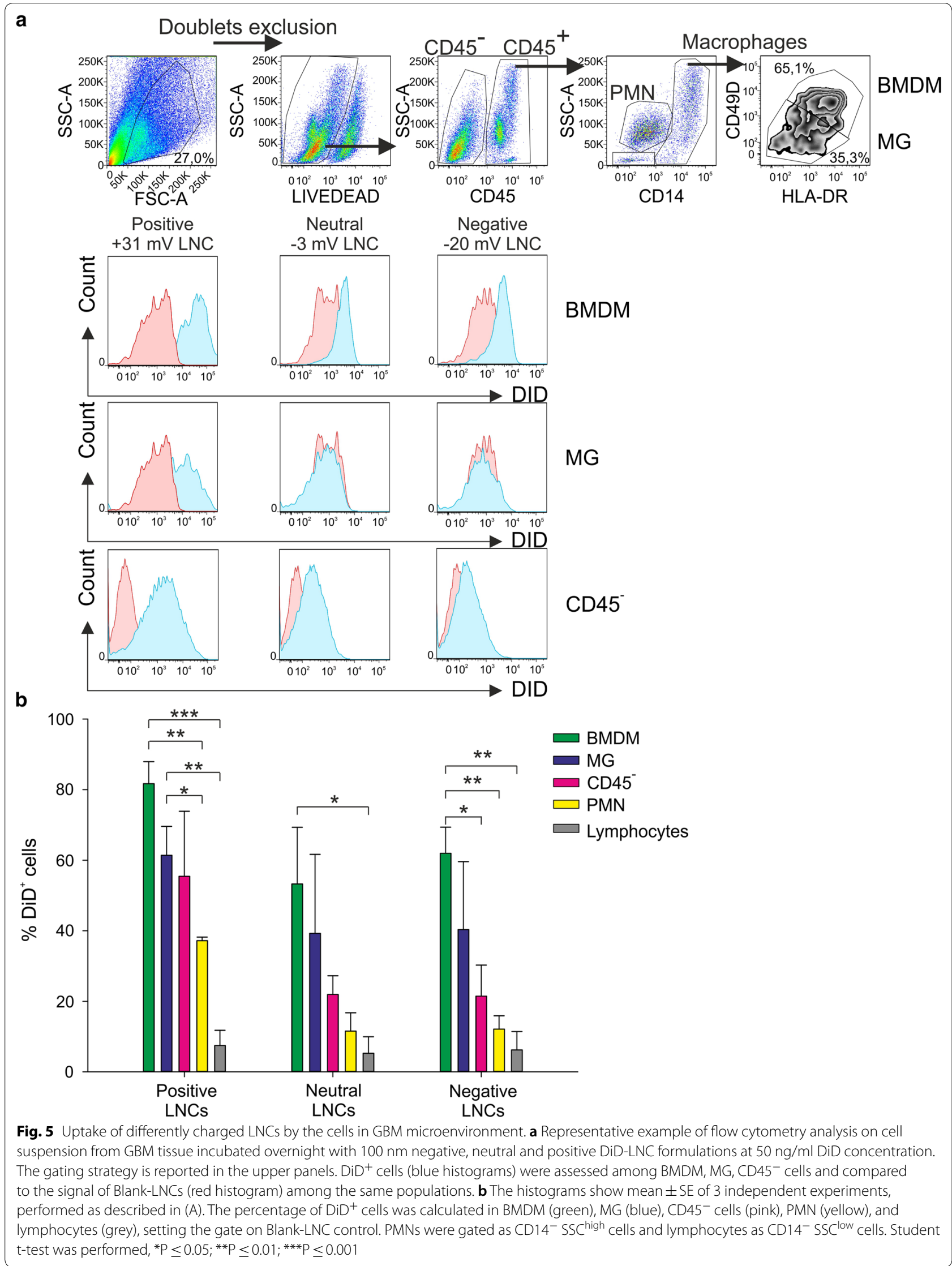


formulations. Moreover, both BMDM and MG cells also reached an uptake significantly higher than PMNs and this LNC formulation also allowed an increased uptake by tumor cells, evaluated as $\mathrm{CD}^{-} 5^{-}$cells (Fig. $5 \mathrm{a}$ and b).

Positively charged LNCs show a very high uptake by B cells from the peripheral blood (Fig. 2b), but B lymphocytes are not present in GBM tumors (data not shown); therefore, these data indicate that $100 \mathrm{~nm}$ positively charged LNCs could be used as a drug-loaded nanosystem to target the main immune suppressive cell subset in these tumors. Moreover, tumor cells also show a significant uptake, thus reinforcing the possibility of using

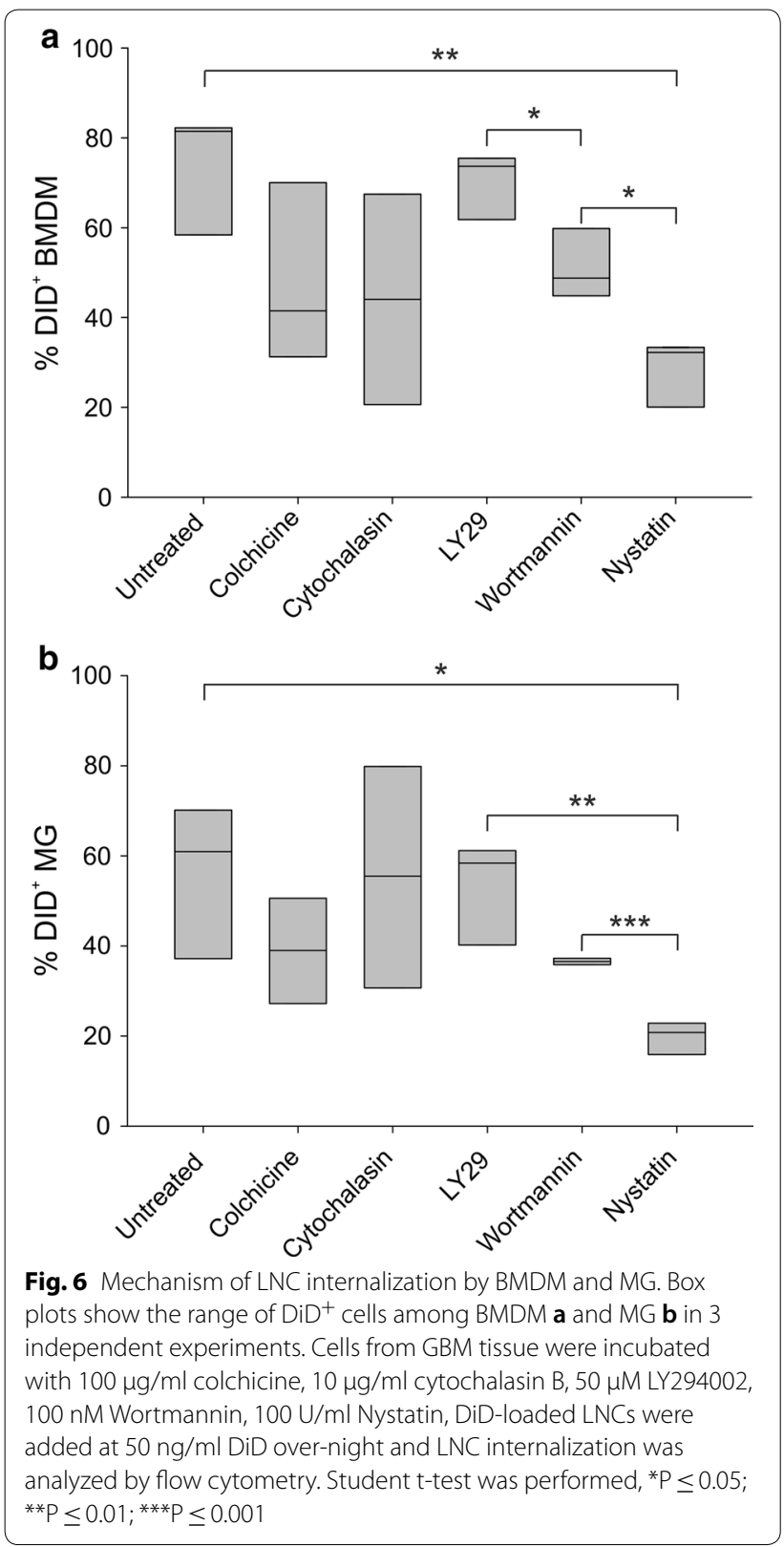

this nanosystem to target both tumor cells and tumorpromoting cells.

\section{Mechanism of LNC internalization by the GBM microenvironment}

Given the high ability of tumor macrophages to internalize positively charged LNCs, we analyzed the mechanism by which these nanoparticles were incorporated by the cells of the tumor microenvironment. We thus treated the cell suspension obtained after enzymatic digestion of GBM tumor tissue with uptake inhibitors and added DiD-loaded LNCs to cell suspensions for overnight incubation. As shown in Fig. 6, internalization by both types of macrophages (BMDM and MG) was significantly reduced by the addition of nystatin, in line with the internalization observed by blood monocytes. A reduction in LNC uptake was also observed using colchicine in both BMDM and MG and cytochalasin B in BMDM, but without statistical significance.

\section{Discussion}

Functionalization of nanosystems offers the opportunity to maximize the protection of associated drug and the targeting properties of the carrier towards the desired cell populations. In this study, we optimized LNCs to target immunosuppressive populations in GBM patients, with the aim of disclosing innovative applications in the field of immunotherapy. Indeed, as recently shown in two pioneer studies of personalized vaccination in GBM patients, the immune system can be activated toward tumor antigens expressed by the tumor but the induction of an immune response does not directly translate into a clinical benefit, likely because other critical aspects of the complex interaction between tumor and immune systems are not yet defined [30, 31]. From several studies, it appears that one of the main obstacles toward a successful anti-tumor immune response is the suppression exerted by myeloid cells on cells of the adaptive immune system. Therefore, we tested known LNC formulations, with slight modifications in size and charge, capable of targeting immune suppressive subsets in cancer patients, but we also evaluated the interactions of LNCs with many subsets of the immune system, including those potentially able to mediate cancer regression, like the $\mathrm{T}$ lymphocytes. To the best of our knowledge, this is the first study to provide a broad picture on the impact of different LNC formulations on human immune cell subsets freshly isolated from GBM patients. We thus extend our previous results focused on immune suppressive myeloid cells in the blood of melanoma patients to different populations of circulating and tumor-associated myeloid cells in GBM patients. The LNC formulations used in the present work were already tested in mouse models and 
proved to be non-toxic, using different administration routes, and effective in reaching tumor site and reducing tumor growth [13-15].

Until now, only a few studies addressed LNC targeting towards MDSCs as a way to either deplete them or to induce their maturation. Aptamer (T1) conjugated to liposomal doxorubicin [32] or lipid-coated biodegradable hollow mesoporous silica nanoparticle co-encapsulated with all-trans retinoic acid (ATRA), doxorubicin and IL-2 [33] showed a high affinity for both tumor cells and PMN-MDSCs [32] or to induce a reduction in the number of MDSCs in the tumor microenvironment of mouse models [33]. However, these systems showed no affinity for M-MDSCs or macrophages therefore reducing their applicability only to tumors in which PMN MDSCs are mainly involved [32]. Besides, they affected other cell subsets present in the tumor microenvironment, and thus cannot be considered a nanosystem with a specific targeting towards MDSCs.

Moreover, Zinc-doped iron oxide nanoparticles modified with polyethylenimine molecules and dimercaptosuccinic acid in combination with radiotherapy prolonged survival of CT-2A mouse glioma model and were mainly incorporated by TAM/MDSCs, although the definition of these cell populations was based only on CD45 and CD11b markers without further characterization [34]. The activity of MDSCs was shown to be modulated also using polyarginine nanocapsules carrying the chemokine CCL2 and an RNAi sequence targeting $\mathrm{C} / \mathrm{EBP} \beta$, a transcriptional factor fundamental for MDSC differentiation and functions [35], thus showing that MDSCs represent an interesting target in a nanomedicine approach.

The idea of using tailored LNCs, encapsulated with selected drugs, to reduce blood monocytes stems from the findings that monocytes are actively recruited at tumor site and sustain the accumulation of immunosuppressive macrophages in the tumor microenvironment of GBM patients [18]. Given the high rate of relapse in GBM patients, targeting blood monocytes should be evaluated as an adjuvant therapy in such patients after surgical resection, to deplete them or to block their function. This strategy would allow the inhibition of the loop through which GBM tumor attracts immunosuppressive cells at tumor site and suppresses the anti-tumor immune response. The stability of neutral $60 \mathrm{~nm}$ LNCs loaded with 5-FU in human plasma was already tested and proved that the system is stable and protected the drug from rapid degradation, thus confirming the potential use of LNCs as a tool to target immunosuppressive cells in peripheral blood of patients [36].

The efficacy of LNCs in the treatment of glioma was demonstrated in GL261 glioma-bearing mice following stereotactic injection. Multifunctional lipid nanocapsules designed to combine the activity of the cytotoxic drug paclitaxel (PTX) with the immunostimulant CpG were intratumorally administered and were able to increase the survival of mice compared to control, i.e. the free Taxol ${ }^{\circledR}$, or PTX-loaded LNCs. This effect was also confirmed by magnetic resonance imaging, which revealed the reduction of tumor growth in the treated animals [13]. Moreover, Vanpouille-Box et al. demonstrated that lipid nanocapsules loaded with rhenium-188 (LNC ${ }^{188}$ Re-SSS) implanted in the brain of a rat orthotopic glioma model triggered remarkable survival responses. A strong activation of myeloid cells assessed by immunohistochemistry was observed in this model together with the recruitment of natural killer and dendritic cells, thus suggesting an improved capacity to develop an antitumor immune response [37]. Another study, performed in a murine glioma model with a different type of nanosystem, i.e. cyclodextrin-based nanoparticle (CDP-NP), demonstrated a predominant uptake of CDP-NP by macrophages and microglia within and around the tumor site [38].

In the present study we optimized an LNC formulation to target immunosuppressive BMDMs in the GBM microenvironment, but documented that also tumor cells incorporate a lower but significant amount of such LNCs, thus demonstrating that this nanosystem might target both tumor cells and tumor-promoting cells. LNC incorporation was observed to a lower extent also in resident MG cells but, since it has been demonstrated that in GBM these cells display an activated phenotype that promotes tumor progression [39] and in the center of tumor lesion they exert a moderate immunosuppressive activity, their targeting by drug-loaded LNC could also be beneficial [18]. Further studies will be required to investigate the effect of these nanoparticles on other immune cell subsets, such as dendritic cells, that have a key role in the modulation of the immune system and are expected to phagocyte LNCs, therefore becoming one of their targets [40]. These results open the road to new strategies of therapeutic interventions. For example, LNCs could be loaded with a drug inducing immunogenic cell death, offering the possibility of eliminating both suppressive macrophages and tumor cells, thus reversing a tolerogenic microenvironment, and providing the rationale for a new treatment of GBM. However, systemic administration would lead to a high uptake by liver, kidney, and spleen, and would not guarantee a sufficient uptake by the tumor $[41,42]$. Thus, to avoid this problem, an intrathecal administration, following tumor resection, could be exploited, in order to maximize local efficacy and reduce systemic side effects. 


\section{Conclusions}

Our study shows that modulation of size and charge of nanosystems impacts the uptake by human blood circulating leukocytes and tumor-infiltrating cells. We exploited such properties to optimize LNC targeting towards immunosuppressive populations, while maintaining a low level of internalization by $\mathrm{T}$ cells. We propose neutral $100 \mathrm{~nm}$ LNCs and positively charged $100 \mathrm{~nm}$ LNCs as the most effective targeting nanosystems respectively in the blood and at tumor site in glioblastoma patients. This study represents a proof of principle that different physico-chemical characteristics of a nanocarrier system can be exploited to target a specific cell subset, while sparing others of therapeutic importance. This approach could be extended to other cancers and set the ground as a new tailored anticancer treatment in the frame of immunotherapy.

\section{Methods}

\section{Patient characteristics}

Patients were recruited at the Department of Neurosurgery, Padova University Hospital, Italy. The ethical committee of the IOV-IRCCS and of Padova University Hospital approved all experiments and all patients gave their informed consent. We analyzed peripheral blood from $12 \mathrm{GBM}$ patients and tumor tissue from $6 \mathrm{GBM}$ patients. The studies were conducted in accordance with the Declaration of Helsinki. To optimize experimental conditions and to test the internalization properties of different LNC formulations, peripheral blood of 15 HDs was analyzed.

\section{Isolation of PBLs and PBMCs from peripheral blood of HDs and GBM patients}

Peripheral blood was collected from HDs and GBM patients and subjected to lysis to remove red blood cells and viable PBLs were counted. PBMCs and PMNs were isolated as previously described [43]. Additional information are described in Additional file 1: Supplementary methods.

\section{GBM tissue processing to obtain a single-cell suspension} GBM tumors were processed immediately after resection, as described in Additional file 1: Supplementary methods, to obtain a single cell suspension without erythrocytes and debris.

\section{Preparation of lipid nanocapsules}

LNC formulation was based on a phase inversion process already described [14, 22]. Different LNCs having a size of 25,50 , and $100 \mathrm{~nm}$ were prepared by varying component amounts according to Table 2.

\section{Physico-chemical characterization of LNCs}

Size, estimated by the average hydrodynamic diameter,

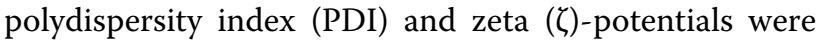
determined by dynamic light scattering (DLS) using NanoZS $^{\circledR}$ (Malvern Instruments, Worcestershire, United Kingdom). Electrophoretic mobility was converted to $\zeta$-potentials using Smoluchowski's equation. Measurements were performed at a $173^{\circ}$ angle after dispersion of $50 \mu \mathrm{L}$ LNCs in $2.95 \mathrm{ml}$ MilliQ water to ensure convenient scattered intensity on the detector. All measurements were performed in triplicate at $25{ }^{\circ} \mathrm{C}$ with comparable conductivity for $\zeta$-potential determination.

\section{LNC incorporation by cell populations in peripheral blood and tumor tissue}

PBLs, PBMCs, or tumor cell suspension obtained as previously described were incubated with LNCs at the final DiD concentration of $50 \mathrm{ng} / \mathrm{ml}$ for $90^{\prime}, 3 \mathrm{~h}$, or overnight at $37{ }^{\circ} \mathrm{C}$. As control, Blank-LNC formulations were used. $10 \mu \mathrm{g} / \mathrm{ml}$ Cytochalasin B (SigmaAldrich), $100 \mu \mathrm{g} / \mathrm{ml}$ Colchicine (Sigma-Aldrich), $50 \mu \mathrm{M}$ LY294002 hydrochloride (Sigma-Aldrich), 100 nM Wortmannin (Sigma-Aldrich), and $100 \mathrm{U} / \mathrm{ml}$ Nystatin were used to test the mechanism of internalization. At the end of the incubation, cells were stained for flow cytometry analysis. Further details are reported in Additional file 1: Supplementary methods.

\section{Multiparametric flow cytometry}

Leukocytes were stained with antibody cocktails in order to define different cell populations as specified in Additional file 1: Supplementary materials and methods. Data acquisition was performed using LSRII flow cytometer (BD Biosciences) and results were analyzed by FlowJo software (Three Star Inc). Further details in Additional file 1: Supplementary methods.

\section{Confocal microscopy}

PBMCs and PMNs were incubated with LNCs and nystatin inhibitor and then prepared for confocal analysis as specified in Additional file 1: Supplementary methods. Samples were analyzed under a laser scanning confocal microscope (Leica TCS SP5, Wetzlar, Germany) equipped with 4 lasers (405 nm/Argon$458,476,488,494,514 \mathrm{~nm}-/ 561 \mathrm{~nm} / 633 \mathrm{~nm})$, and results were analyzed by Las X (Leica MICROSYSTEMS).

\section{Statistical analysis}

The Mann-Whitney and the Student t-test were used as appropriate and performed by Sigmaplot software (Systat Software Inc., CA, USA). 


\section{Supplementary information}

Supplementary information accompanies this paper at https://doi. org/10.1186/s12951-020-00589-3.

Additional file 1. Supplementary materials and methods. Isolation of cell populations from peripheral blood and tissue of GBM patients, preparation of lipid nanocapsules, LNC incorporation studies, multiparametric flow cytometry, confocal microscopy, statistical analysis.

\section{Abbreviations}

ATRA: All-trans retinoic acid; BM: Bone-marrow; BMDM: Bone marrow-derived macrophages; eMDSC: Early-stage MDSC; GBM: Glioblastoma multiforme; GemC12: Lauroyl-modified form of gemcitabine; HD: Healthy donor; LNC: Lipid nanocapsule; MG: Microglia; MDSC: Myeloid derived suppressor cell; M-MDSC: Monocytic MDSC; PTX: Paclitaxel; PBMC: Peripheral blood mononuclear cell; PMN: Polymorphonuclear cell; PMN-MDSC: Polymorphonuclear MDSC; TAM: Tumor-associated macrophage.

\section{Acknowledgements}

The authors thank P. Gallo for artwork.

\section{Authors' contributions}

$L P, S M, E M, M V, I S, V I$ performed the experiments and analyzed the data. SM and LP wrote the manuscript. KM and JPB produced lipid nanocapsules and discussed the data. GL produced lipid nanocapsules, discussed the data and was involved in manuscript writing. VB and IM discussed data, made critical revision and participated in manuscript writing. ADP performed neurosurgery, provided clinical information and discussed the results. SM designed the research, handled funding and supervised the work. All authors read and approved the final manuscript.

\section{Funding}

This work was supported by the Italian Association for Cancer Research (AIRC) (IG2015-17400 to S.M; 18603 and 12182 that refers to the Special Program Molecular Clinical Oncology 5 per mille to V.B.), by grants from Università degli Studi di Padova (CPDA-144873 to S.M.), EuroNanoMed II 2013 (NICHE), Euronanomed III (Joint Translational Call 2017, Project Resolve), the Cancer Research Institute (Clinic and Laboratory Integration Program, CLIP 2017), and the Cariverona Foundation (Project call, 2017).

\section{Availability of data and materials}

Not applicable.

\section{Ethics approval and consent to participate}

The ethical committee of the IOV-IRCCS and of Padova University Hospital approved all experiments and all patients gave their informed consent.

\section{Consent for publication}

Not applicable.

\section{Competing interests}

The authors declare that they have no competing interests.

\section{Author details}

${ }^{1}$ Veneto Institute of Oncology IOV-IRCCS, Padua, Italy. ${ }^{2}$ Department of Surgery, Oncology and Gastroenterology, University of Padova, Via Gattamelata 64, 35128 Padua, Italy. ${ }^{3}$ Pharmacy Department, Academic Hospital, 4 rue Larrey, Angers, France. ${ }^{4}$ Micro et Nanomedecines Translationnelles, MINT, UNIV Angers, UMR INSERM 1066, UMR CNRS 6021, Angers, France. ${ }^{5}$ Neurosurgery Unit, Azienda Ospedaliera di Padova, Padua, Italy. ${ }^{6}$ Department of Medicine, Section of Immunology, University of Verona, Verona, Italy. ${ }^{7}$ Univ Lyon, Université Claude Bernard Lyon 1, CNRS, LAGEPP UMR 5007, 69100 Villeurbanne, France. ${ }^{8}$ Present Address: Department of NEUROFARBA, University Hospital of Careggi, University of Florence, Florence, Italy.

Received: 9 December 2019 Accepted: 30 January 2020 Published online: 17 February 2020

\section{References}

1. Shao K, Singha S, Clemente-Casares $X$, Tsai S, Yang Y, Santamaria P. Nanoparticle-based immunotherapy for cancer. ACS Nano. 2015;9(1):16-30.

2. Lu J, Liu X, Liao YP, Salazar F, Sun B, Jiang W, et al. Nano-enabled pancreas cancer immunotherapy using immunogenic cell death and reversing immunosuppression. Nat Commun. 2017;8(1):1811.

3. He H, Ghosh S, Yang H. Nanomedicines for dysfunctional macrophageassociated diseases. J Control Release. 2017;247:106-26.

4. Kranz LM, Diken M, Haas H, Kreiter S, Loquai C, Reuter KC, et al. Systemic RNA delivery to dendritic cells exploits antiviral defence for cancer immunotherapy. Nature. 2016;534(7607):396-401.

5. Jiao Q, Li L, Mu Q, Zhang Q. Immunomodulation of nanoparticles in nanomedicine applications. Biomed Res Int. 2014;2014:426028.

6. Cabral H, Matsumoto Y, Mizuno K, Chen Q, Murakami M, Kimura M, et al. Accumulation of sub-100 nm polymeric micelles in poorly permeable tumours depends on size. Nat Nanotechnol. 2011;6(12):815-23.

7. Ovais M, Guo M, Chen C. Tailoring nanomaterials for targeting tumorassociated macrophages. Adv Mater. 2019;31:e1808303.

8. Bronte V, Brandau S, Chen SH, Colombo MP, Frey AB, Greten TF, et al. Recommendations for myeloid-derived suppressor cell nomenclature and characterization standards. Nat Commun. 2016;7:12150.

9. Biswas SK, Mantovani A. Macrophage plasticity and interaction with lymphocyte subsets: cancer as a paradigm. Nat Immunol. 2010;11(10):889-96.

10. Mantovani A, Marchesi F, Malesci A, Laghi L, Allavena P. Tumourassociated macrophages as treatment targets in oncology. Nat Rev Clin Oncol. 2017;14(7):399-416.

11. Fleming $V$, Hu X, Weber R, Nagibin V, Groth C, Altevogt $P$, et al. Targeting myeloid-derived suppressor cells to bypass tumor-induced immunosuppression. Front Immunol. 2018;9:398.

12. Garcion E, Lamprecht A, Heurtault B, Paillard A, Aubert-Pouessel A, Denizot B, et al. A new generation of anticancer, drug-loaded, colloidal vectors reverses multidrug resistance in glioma and reduces tumor progression in rats. Mol Cancer Ther. 2006;5(7):1710-22.

13. Lollo G, Vincent M, Ullio-Gamboa G, Lemaire L, Franconi F, Couez D, et al. Development of multifunctional lipid nanocapsules for the codelivery of paclitaxel and CpG-ODN in the treatment of glioblastoma. Int J Pharm. 2015:495(2):972-80.

14. Sasso MS, Lollo G, Pitorre M, Solito S, Pinton L, Valpione S, et al. Low dose gemcitabine-loaded lipid nanocapsules target monocytic myeloid-derived suppressor cells and potentiate cancer immunotherapy. Biomaterials. 2016;96:47-62.

15. Hirsjarvi S, Sancey L, Dufort S, Belloche C, Vanpouille-Box C, Garcion E, et al. Effect of particle size on the biodistribution of lipid nanocapsules: comparison between nuclear and fluorescence imaging and counting. Int J Pharm. 2013;453(2):594-600.

16. Gabrusiewicz K, Rodriguez B, Wei J, Hashimoto Y, Healy LM, Maiti $\mathrm{SN}$, et al. Glioblastoma-infiltrated innate immune cells resemble MO macrophage phenotype. JCI Insight. 2016;1 (2):e85841. https://doi. org/10.1172/jci.insight.85841.

17. Bowman RL, Klemm F, Akkari L, Pyonteck SM, Sevenich L, Quail DF, et al Macrophage ontogeny underlies differences in tumor-specific education in brain malignancies. Cell Rep. 2016;17(9):2445-59.

18. Pinton L, Masetto E, Vettore M, Solito S, Magri S, D'Andolfi M, et al. The immune suppressive microenvironment of human gliomas depends on the accumulation of bone marrow-derived macrophages in the center of the lesion. J Immunother Cancer. 2019;7(1):58.

19. Wang Z, Zhang C, Liu X, Wang Z, Sun L, Li G, et al. Molecular and clinical characterization of PD-L1 expression at transcriptional level via 976 samples of brain glioma. Oncoimmunology. 2016;5(11):e1196310.

20. Berghoff AS, Kiesel B, Widhalm G, Wilhelm D, Rajky O, Kurscheid S, et al. Correlation of immune phenotype with IDH mutation in diffuse glioma. Neuro Oncol. 2017;19(11):1460-8.

21. Chen Z, Hambardzumyan D. Immune Microenvironment in Glioblastoma Subtypes. Front Immunol. 2018;9:1004.

22. Heurtault B, Saulnier P, Pech B, Proust JE, Benoit JP. A novel phase inversion-based process for the preparation of lipid nanocarriers. Pharm Res. 2002;19(6):875-80.

23. Le Roux G, Moche H, Nieto A, Benoit JP, Nesslany F, Lagarce F. Cytotoxicity and genotoxicity of lipid nanocapsules. Toxicol In Vitro. 2017:41:189-99. 
24. Vinogradov SV, Bronich TK, Kabanov AV. Nanosized cationic hydrogels for drug delivery: preparation, properties and interactions with cells. Adv Drug Deliv Rev. 2002;54(1):135-47.

25. He C, Hu Y, Yin L, Tang C, Yin C. Effects of particle size and surface charge on cellular uptake and biodistribution of polymeric nanoparticles. Biomaterials. 2010;31(13):3657-66.

26. Dunning MD, Lakatos A, Loizou L, Kettunen M, Ffrench-Constant C, Brindle KM, et al. Superparamagnetic iron oxide-labeled Schwann cells and olfactory ensheathing cells can be traced in vivo by magnetic resonance imaging and retain functional properties after transplantation into the CNS. J Neurosci. 2004;24(44):9799-810.

27. Araki N, Hatae T, Furukawa A, Swanson JA. Phosphoinositide-3-kinaseindependent contractile activities associated with Fcgamma-receptormediated phagocytosis and macropinocytosis in macrophages. J Cell Sci. 2003;116(Pt 2):247-57.

28. Araki N, Johnson MT, Swanson JA. A role for phosphoinositide 3-kinase in the completion of macropinocytosis and phagocytosis by macrophages. J Cell Biol. 1996;135(5):1249-60.

29. Ros-Baro A, Lopez-Iglesias C, Peiro S, Bellido D, Palacin M, Zorzano A, et al. Lipid rafts are required for GLUT4 internalization in adipose cells. Proc Natl Acad Sci U S A. 2001;98(21):12050-5.

30. Hilf N, Kuttruff-Coqui S, Frenzel K, Bukur V, Stevanovic S, Gouttefangeas $C$, et al. Actively personalized vaccination trial for newly diagnosed glioblastoma. Nature. 2019:565(7738):240-5.

31. Keskin DB, Anandappa AJ, Sun J, Tirosh I, Mathewson ND, Li S, et al. Neoantigen vaccine generates intratumoral T cell responses in phase Ib glioblastoma trial. Nature. 2019;565(7738):234-9.

32. Liu H, Mai J, Shen J, Wolfram J, Li Z, Zhang G, et al. A Novel DNA Aptamer for dual targeting of polymorphonuclear myeloid-derived suppressor cells and tumor cells. Theranostics. 2018;8(1):31-44.

33. Kong M, Tang J, Qiao Q, Wu T, Qi Y, Tan S, et al. Biodegradable hollow mesoporous silica nanoparticles for regulating tumor microenvironment and enhancing Antitumor efficiency. Theranostics. 2017;7(13):3276-92.

34. Wu C, Muroski ME, Miska J, Lee-Chang C, Shen Y, Rashidi A, et al. Repolarization of myeloid derived suppressor cells via magnetic nanoparticles to promote radiotherapy for glioma treatment. Nanomedicine. 2019;16:126-37.

35. Ledo AM, Sasso MS, Bronte V, Marigo I, Boyd BJ, Garcia-Fuentes M, et al. Co-delivery of RNAi and chemokine by polyarginine nanocapsules enables the modulation of myeloid-derived suppressor cells. J Control Release. 2019;295:60-73.

36. Lollo G, Matha K, Bocchiardo M, Bejaud J, Marigo I, Virgone-Carlotta A, et al. Drug delivery to tumours using a novel 5-FU derivative encapsulated into lipid nanocapsules. J Drug Target. 2019;27(5-6):634-45.

37. Vanpouille-Box C, Lacoeuille F, Belloche C, Lepareur N, Lemaire L, LeJeune $J$, et al. Tumor eradication in rat glioma and bypass of immunosuppressive barriers using internal radiation with (188)Re-lipid nanocapsules. Biomaterials. 2011;32(28):6781-90.

38. Alizadeh D, Zhang L, Hwang J, Schluep T, Badie B. Tumor-associated macrophages are predominant carriers of cyclodextrin-based nanoparticles into gliomas. Nanomedicine. 2010;6(2):382-90.

39. Roesch S, Rapp C, Dettling S, Herold-Mende C. When immune cells turn bad-tumor-associated microglia/Macrophages in glioma. Int J Mol Sci. 2018;19(2):436.

40. Dacoba TG, Olivera A, Torres D, Crecente-Campo J, Alonso MJ. Modulating the immune system through nanotechnology. Semin Immunol. 2017;34:78-102.

41. Blanco E, Shen H, Ferrari M. Principles of nanoparticle design for overcoming biological barriers to drug delivery. Nat Biotechnol. 2015;33(9):941-51.

42. Nduom EK, Bouras A, Kaluzova M, Hadjipanayis CG. Nanotechnology applications for glioblastoma. Neurosurg Clin N Am. 2012;23(3):439-49

43. Mandruzzato S, Solito S, Falisi E, Francescato S, Chiarion-Sileni V, Mocellin S, et al. IL4Ralpha + myeloid-derived suppressor cell expansion in cancer patients. J Immunol. 2009;182(10):6562-8.

\section{Publisher's Note}

Springer Nature remains neutral with regard to jurisdictional claims in published maps and institutional affiliations.
Ready to submit your research? Choose BMC and benefit from:

- fast, convenient online submission

- thorough peer review by experienced researchers in your field

- rapid publication on acceptance

- support for research data, including large and complex data types

- gold Open Access which fosters wider collaboration and increased citations

- maximum visibility for your research: over 100M website views per year

At BMC, research is always in progress.

Learn more biomedcentral.com/submissions 